\title{
Infectious diarrhea, as public health problem, in Romania
}

Liana Monica Deac

National Public Health Institute, Public Health Center, Cluj- Napoca.

Correspondence Author: Liana Monica Deac, National Public Health Institute, Public Health Center, Cluj- Napoca.

Received date: February 20, 2021; Accepted date: March 09, 2021; Published date: March 18, 2021

Citation: Liana M. Deac. (2021) Infectious diarrhea, as public health problem, in Romania. Clinical Medical Reviews and Reports 3(3); DOI:10.31579/2690-8794/070

Copyright: (C2021 Liana Monica Deac, This is an open access article distributed under the Creative Commons Attribution License, which permits unrestricted use, distribution, and reproduction in any medium, provided the original work is properly cited.

\begin{abstract}
From medical point of view, "Diarrhea" is an alteration in a normal bowel movement characterized by an increase in the water content, volume, or frequency of stools. Acute diarrhea of infectious etiology, often referred to as gastroenteritis and is typically associated with clinical signs and symptoms including: nausea, vomiting, abdominal pain and cramps, bloating, flatulence, fever, passage of bloody stools, tenesmus, and fecal urgency. Infectious diarrheal diseases are the second leading cause of morbidity and mortality worldwide. It is the diarrhea we have also found out, during a large 3 yeas study 2017-2020 in Transylvania - Romania. 3577 number of cases were transmitted during this time, to our Public Health Center, by 12 district Sanitary Polices. These were mostly diagnosed by the territorial family doctors and more than $50 \%$, have need hospitalization, for several days because of the mentioned disease disorders. The detected infectious etiology, were determined in authorized laboratories in which it was identified: Shigella, Salmonella, Campylobacter, and Yersinia, Rotavirus, Giardia. Most number of cases appeared in children, followed by elderly or adult people, as quantified number of determination.

In light of these data, acute diarrheal illness had to be considered a major public health issue against which control efforts are needed. Public health surveillance and response in the field of infectious acute diarrhea include obligatory strategies of infection control.
\end{abstract}

Key words: diarrhea symptoms, etiology, health survey

\section{Introduction}

According to the World Health Organization (WHO) and UNICEF, there are about 2 billion cases of diarrheal disease worldwide every year, and 1.9 million children younger than 5 years of age perish from diarrhea each year, mostly in developing countries. In industrialized countries, relatively few patients die from diarrhea, but the disease continues to be an important cause of morbidity that is associated with substantial health care costs. However, the morbidity from diarrheal diseases has remained relatively constant during the past 2 decades [4].

Because off all these data, it was studied in the Epidemiology Department, of the Public Health Center, 3 years long, during 2017 - 2020, the morbidity caused by infectious diarrhea, which appeared in Transylvania region-Romania. Despite the economic and societal burdens of diarrheal illnesses, few clinical guidelines exist worldwide for the diagnosis and treatment of persons with suspected infectious diarrhea. That for considerable clinical practice has to be observed and demonstrate a clear need for a clinical diagnostic improved guideline.

\section{Material and method}

By using an analytical descriptive epidemiological study, there were analyzed 3577 cases of infectious diarrhea in population, for to figure out all representative aspects of these pathology in: children, adults and elderly people. Data recruitment were ordered by the Ro national public health guidelines and were transmitted yearly by the territory sanitary police units, on each 3 study years, during 5 months, from May to November and sent to the Public Health Center Cluj- Epidemiology Department, where it was done the epidemiologic study and all received data interpretations.

\section{Results and comments}

Infectious diarrhea in total of 3577 number, was present in Transylvania region- Ro, as shown relevant data for a yearly comment, as it is figured out in Figure 1. 


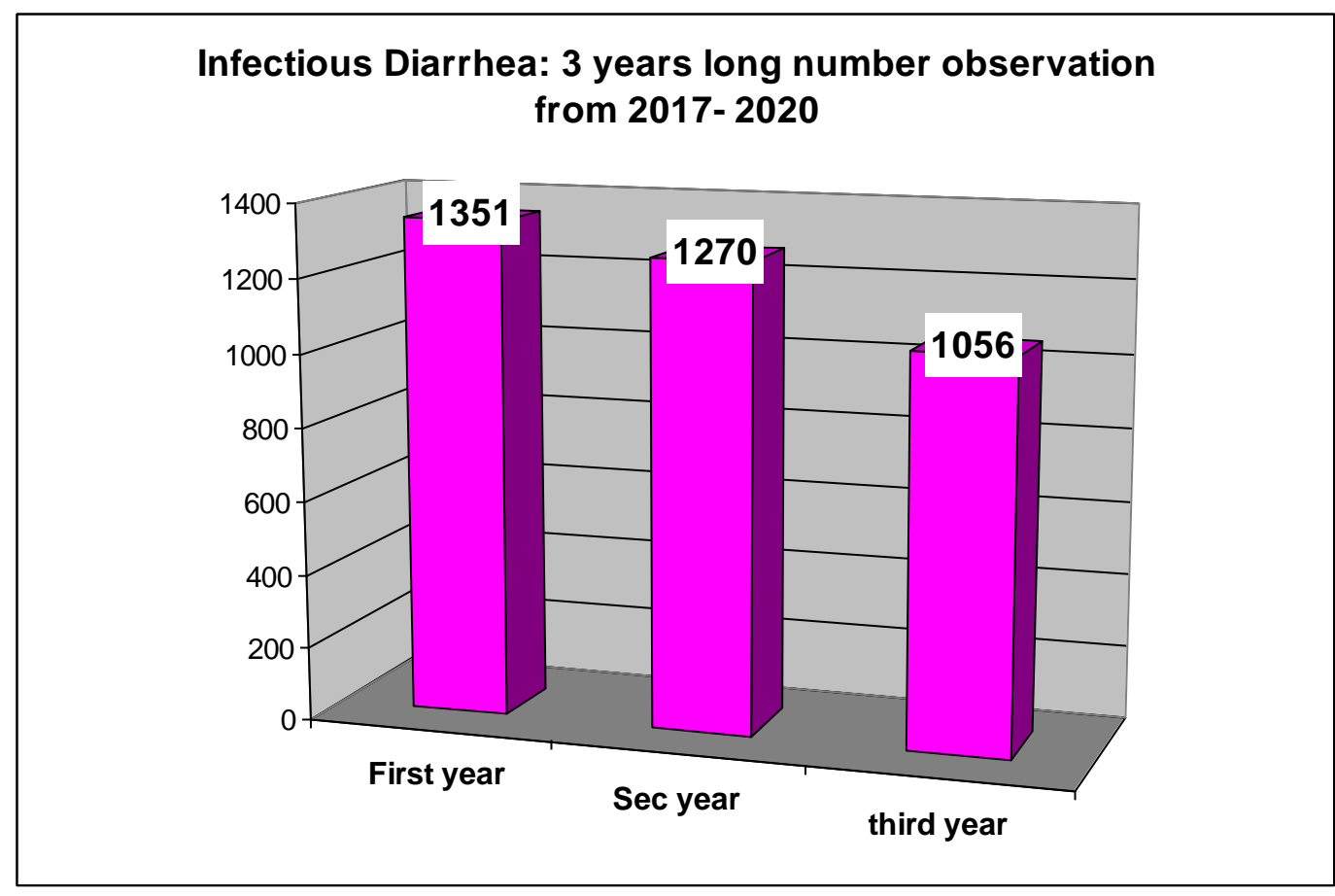

Figure 1. Infectious diarrhea during 2017-2020

Most of the disease were present in the first year in the study, in 37\%, followed by $35.5 \%$ in the second year and at least in $29.5 \%$ in the third one. In all 3 years, most of this pathology appeared in the summer season and almost during July to August, in our entire studied territory and it was not a significant estimate difference, between the yearly done activities for it. The case incidence for the disease arrived at $65 \%$ in the seasonal morbidity, and was represented in special during the mentioned summer months, July and August.

Significant to be figured out was even, that infectious diarrhea existed at each age decade, but more significant in children with 63\%, as Figure 2 present data.

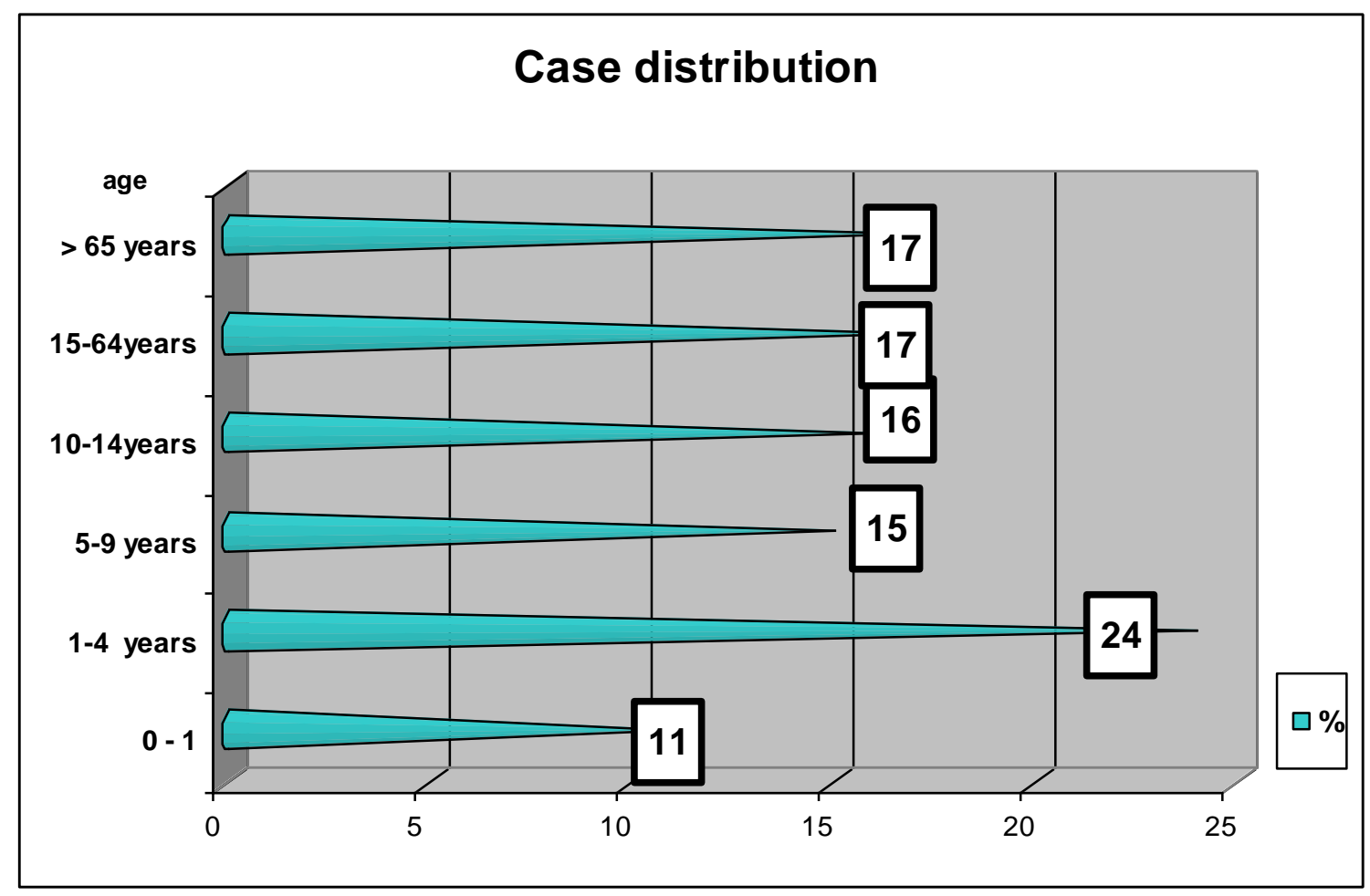


The disease was at children during 0-14 age representative present. Most children on the decade 1-4 age were the reported cases. In adults infectious diarrhea was remarked in $17 \%$, as well in elderly people this pathology was represented in same number also, by $17 \%$. $27 \%$ of cases from children and adults have need short hospitalization times accused of dehydration, during the entire mentioned period of the observation and it was used a specific with adequate fluid and electrolyte replacement and with maintenance were the key treatment to managing diarrheal illnesses. Even so, 3 children under 5 years age died, after this specific therapy, because of severe complications. Organic failed was estimate to be the cause of their deaths.

There is also a growing awareness of the potentially huge impact, in the developing world, of long-term disability caused by repeated early childhood enteric infections. It is estimated that, worldwide, there are 3.1 million deaths due to diarrhea per year (18400 per day), mostly of young children in developing areas [1]. Annual deaths due to diarrhea globally occur mainly in young children, and the number of deaths is 1000 -fold higher than in the United States, where most of those who die of diarrheal illness are elderly [2].

Thorough clinical and epidemiological evaluation must define the severity and type of illness. For clinicians, early diagnosis of an acute episode of diarrhea, can lead to interventions that alleviate symptoms and prevent secondary possible transmission. For public health practitioners, prompt notification of pathogen-specific diagnoses and bacterial isolates through public health surveillance, can lower rates of transmission and lead to timely detection and control of outbreaks. Because both clinicians and public health practitioners share overlapping responsibilities for the diagnosis, management, and prevention of infectious diarrheal diseases, must contain recommendations and specific guidelines for both groups [5].

Diarrheal illness is a problem worldwide, with substantial regional variation in the prevalence of specific pathogens. Diagnostic testing of stool specimens was indicated for patients, up to an existing national guideline to identify them. That for it was significant to be figured out, the etiological aspects concerning all detected infectious diarrhea. That for, it was used all date which came from the several territory laboratories as investigation. All this data were identified, in order to present the microbiological discovered aspects, in the several presented situations, during the 3 years study. With, it was possible to make an overview concerning the heterogenic microorganisms, who made the appearance of the infectious diarrhea diseases in the Transylvania population. The incidence of this aspect, is presented in Figure 3.

\section{Incidence of microbiological etiology}

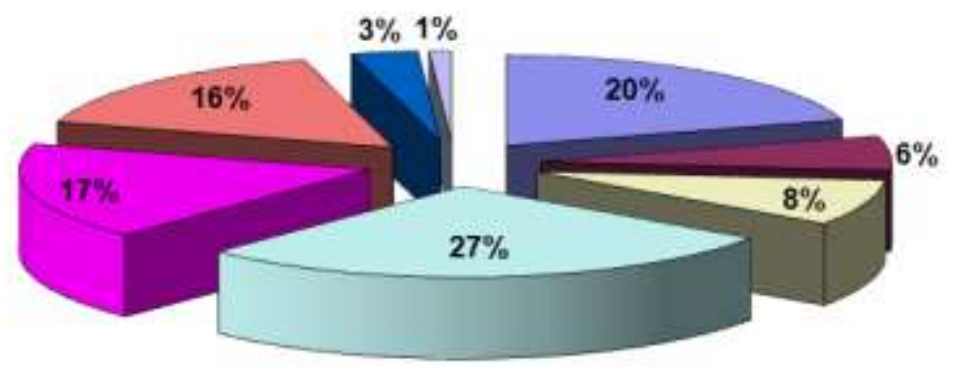

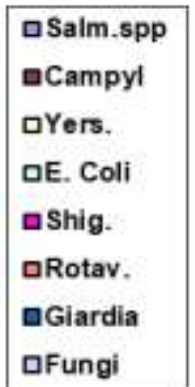

Figure 3. Overview of the detected etiological aspects

Most of species belonged to the Enterobacteriaceae Family, represented by E coli in $27 \%$ Salmonella spp. in $20 \%$; Shigella spp. in $17 \%$. Important is to be figured out here even, that the death of the 3 children under 5 age was caused by invasive $E$. coli, present in their stool samples. Natural, it is also important to be remarked the presence of Yersinia spp in $8 \%$ and of Campylobacter spp in $6 \%$ in other patients samples. The presence of this different bacterial aspects, were for $E$. Coli in the disease cases, at almost in children faces identified, but all other mentioned species were even in adults, or elderly people samples, detected by the territory laboratories.

The observation of this study, even must mention in $17 \%$ the Rotavirus cause, which mostly were present in the infectious diarrhea of children as etiological aspect. $3 \%$ of children have had even Giardia and 1\% of elderly people have had Fungi in their preserved tools. Many of these organisms are easily transmitted through food or water or from one person to another as the epidemiological study figured out results in the territory. 
There are various interpretations of what is considered medically indicated for evaluating persons with diarrhea. Stool cultures are often viewed as tests with a high importance [3].

With the rapid globalization and industrialization of our food supply and with a multiplicity of recognized pathogens and diagnostic tools, the challenges of determining optimal, cost-effective means for appropriate diagnosis, clinical management, and public health control of diarrheal illnesses are great [6]. This will continue to evolve as improved understanding of pathogenesis and development and use of inexpensive, rapid tests improve diagnosis and management of infectious diarrheal illness, one of the most common clinical syndromes in our society. The lack of a specific diagnosis can hinder appropriate management and treatment of many infections. Observation of patients is a recommendations intended to provide clinicians and public health practitioners with a consensus-based document that will aid in the management of acute diarrhea by addressing which patients to test, what tests to order, next what medical treatments to use, and what steps to take to ensure that appropriate public health actions are implemented.

\section{Conclusions}

There was no specific difference of data in the 3 years done study and infectious diarrhea appeared then almost during the summer months.

Children were more involved in the infectious diarrhea incidence, but each patient should be observed about potential epidemiological risk factors, for any diarrheal diseases, or for their possible spread in the territory.
Infection causes, as bacterial, viral, and parasitic, were present among all cases, as the guidelines for the pathology were recommended to be detected in the done study.

All diarrheal pathogens had to be identified, for evaluating persons with the disease and to identify each enteric infections that require specific control measures in clinics and health care activity group.

To reduce the morbidity and mortality associated with infectious diarrhea, needs clinical and public health studies which must work closely done, to identify optimal diagnostic, treatment, and prevention methods.

\section{References}

1. Adkins HJ, Escamilla J, Santiago LT, et al. (1987) Two-year survey of etiologic agents of diarrheal disease at San Lazaro Hospital,Manila Republic of the Philippines. J Clin Microbiol. 25 1143-1147.

2. Matthew R. Riley R, Dorsey Bass, in Pediatric Gastroenterology, 2008

3. Guerrant RL, Van Gilder T, Steiner TS, et al. (2001) Infectious Diseases Society of America. Practice guidelines for the management of infectious diarrhea. Clin Infect Dis. 32(3):331351.

4. Snyder JD, Merson MH. (1982) The magnitude of the global problem of acute diarrheal disease: a review of active surveillance, data. Bull, WHO. 60:605-613.

5. WHO Program for the Control of Diarrhoeal Diseases. CD update on persistent diarrhea. No.4, March 1989.

6. WHO. The management and prevention of acute diarrhoea: practical guidelines. 3d ed. Geneva: World Health Organization

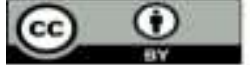

This work is licensed under Creative Commons Attribution 4.0 License

To Submit Your Article Click Here: Submit Manuscript

DOI: $10.31579 / 2690-8794 / 070$
Ready to submit your research? Choose Auctores and benefit from:

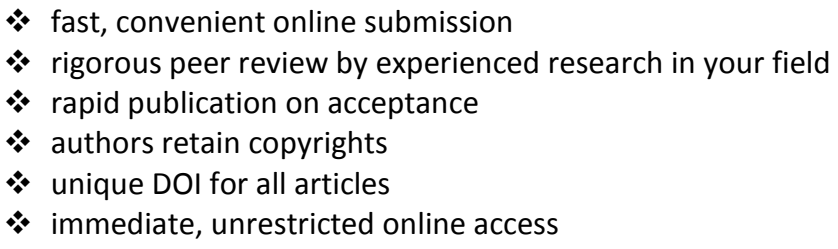

At Auctores, research is always in progress.

Learn more www.auctoresonline.org/journals/clinical-medical-reviewsand-reports 